\title{
Amorphous Mesoporous Titania with High Surface Area for High-Capacity Lithium Storage
}

\author{
Shingo Hamaguchi and Hideaki Yoshitake* \\ *Division of Materials Science and Chemical Engineering, Graduate School of Engineering, Yokohama National \\ University (79-5 Tokiwadai, Hodogaya-ku, Yokohama 240-8501, Japan)
}

Received November 27, 2008 ; Accepted March 7, 2009

\begin{abstract}
The Li storage in mesoporous titania was investigated with varying the framework and porous structure by changing the calcination temperature. By the calcination at $673 \mathrm{~K}$, the amorphous framework was converted into anatase, which is accompanied with the lost of angle X-ray diffraction peak around $2 \theta=2.4^{\circ}$ and with an increase of mesopore diameter. The crystallite size increased while the specific surface area decreased with the increase of calcination temperature. The amorphous framework structure was further analysed by Raman spectroscopy and transmission microscopy. The charge-discharge curves were measured for all mesoporous titanias analysed. The maximum capacity was $225 \mathrm{mAh} \mathrm{g}^{-1}$, which was recorded for $773 \mathrm{~K}$-calcined mesoporous titania. The distinct plateaux appeared in mesoporous anatase and the voltage gap between the plateaux in charge and discharge processes decreased with the calcination temperature. The electrochemical behavior was discussed in relation with the meso- and microscopic structures of the material.
\end{abstract}

Key Words : Mesoporous Titania, Mesoporous Anatase, Crystallization, Lithium Storage, Reversibility

\section{Introduction}

Recently, nanostructured titania have attracted great attention for an electrode material for rechargeable lithium batteries. Significant enhancement of the storage capacity and rate of $\mathrm{Li}$ insertion/extraction in nanocrystalline anatase $^{1)}$ and rutile ${ }^{2,3)}$ has revealed new possibilities of these conventional crystals. In addition, Li insertion into relatively "new" titania crystals such as $\mathrm{TiO}_{2}(\mathrm{H})^{4)}{ }^{4} \mathrm{TiO}_{2}(\mathrm{R})^{5}$ and $\mathrm{TiO}_{2}(\mathrm{~B})^{6)}$ has been investigated with a special interest in their crystalline structures and high capacities of Li storage. The ordered mesoporous structure, which is formed with the aid of appropriate templates, has been one of the important research fields of nanostructured materials. Several mesoporous and crystalline structures have been reported on mesoporous titania. ${ }^{7-10)}$ However, most of the studies on the Li insertion into mesoporous titania has been carried out for the crystalline phases ${ }^{1-144}$ and the data from the amorphous phase is quite limited. ${ }^{15)}$

In the study of amorphous mesoporous titania prepared with dodecylamine template, we have demonstrated unique structural properties, such as a high population of $\mathrm{Ti}$ atoms in 5-fold coordination, i.e. [5-fold Ti]/([5fold Ti $]+[4$-fold Ti $]$ ) $=0.37$, and a large disorder in the chemical bonds. ${ }^{16)}$ The framework remains amorphous after the calcination under $653 \mathrm{~K}$, the calcination between 673 and $773 \mathrm{~K}$ results in the crystallization into anatase, which is accompanied by the appearance of new mesoporous structure. ${ }^{17)}$ In this study, we examine the possibility of $\mathrm{Li}$ storage in mesoporous titania in the amorphous phase with varying the framework structure by calcination.

\section{Experimental}

Mesoporous titania (meso $\mathrm{TiO}_{2}$ ) was prepared as follows. Dodecylamine (1.30 g, Wako Pure Chemical) was mixed with water $(20.0 \mathrm{~g})$ in a beaker and it was maintained at $313 \mathrm{~K}$. Titanium tetraisopropoxide ( $4.0 \mathrm{~g}$, Tokyo Kasei) was added to the mixture at $273 \mathrm{~K}$. After the addition of small amount of $0.1 \mathrm{M} \mathrm{HCl}\left(0.8 \mathrm{~cm}^{3}\right)$, the mixture was allowed to stand for $24 \mathrm{~h}$ and then transferred to a Teflon container in an oven at $333 \mathrm{~K}$. After $4 \mathrm{~d}$, the solution was filtered and washed with ethanol. The resulting white solid was transferred into a test tube and heated in vacuum at $453 \mathrm{~K}$ for $2 \mathrm{~h}$, before the tube was sealed and heated at $453 \mathrm{~K}$ for $10 \mathrm{~d}$. The solid was then washed by stirring in $0.1 \mathrm{~N}$ ethanol solution of $p$-toluenesulfonic acid (Wako Pure Chemical) and in ethanol. After collected and dried at $373 \mathrm{~K}$, the mesoporous titania (extracted meso $\mathrm{TiO}_{2}$ ) powder was stored under dry conditions.

The above prepared titania was calcined at various temperatures. The structure was analysed by X-ray diffraction (XRD) and nitrogen adsorption. The Raman spectra were measured with a JASCO NRS-3100 spectrometer using a green laser at $532 \mathrm{~nm}$. The slit width was $0.200 \mathrm{~mm}$. The output power was $3 \mathrm{~mW}$. The data were collected three times and the number of spectra measured for each sample was 10 - 50. No shifting or line broadening of the peaks occurred during the record of the spectra.

For moulding the working electrode in Li dischargecharge experiments, mesoporous titania powder and acetylene black carbon were mixed with PTFE dispersion. The weight ratio was 80: 15: 5. The paste was pressed into a $12 \mathrm{~mm}$-diameter disk with an aluminium mesh. Metallic lithium and $1 \mathrm{~mol} \mathrm{~kg}^{-1} \mathrm{LiPF}_{6}-\mathrm{EC} / \mathrm{DMC}$ 
were used for the counter electrode and electrolyte, respectively. The electrodes and electrolyte solution were fixed in a two-electrode cell with a separator, with which galvanostatic discharge-charge measurements were performed.

\section{Results and Discussion}

Figure 1 shows XRD of mesoporous titania calcined at various temperatures. A prominent peak is observed at $2 \theta=2.4^{\circ} \quad(d=3.7 \mathrm{~nm})$ in extracted meso $\mathrm{TiO}_{2}$. This peak is not accompanied by higher order diffractions. The diffraction pattern agrees with the wormhole-like structural motif observed in the previous study. ${ }^{10)}$ The peak gradually decreases with the calcination temperature and finally disappears at $673 \mathrm{~K}$. On the other hand, in the region at $2 \theta=10^{\circ}-50^{\circ}$, no peak is found in the diffraction profile from extracted meso $\mathrm{TiO}_{2}$. The pattern does not change at the calcination at 573 and $623 \mathrm{~K}$, suggesting that the framework structure of meso $\mathrm{TiO}_{2}$ is amorphous below $623 \mathrm{~K}$. After the calcination at $673 \mathrm{~K}$, the peaks appear at $25.2^{\circ}, 37.4^{\circ}$ and $47.8^{\circ}$, which are attributed to
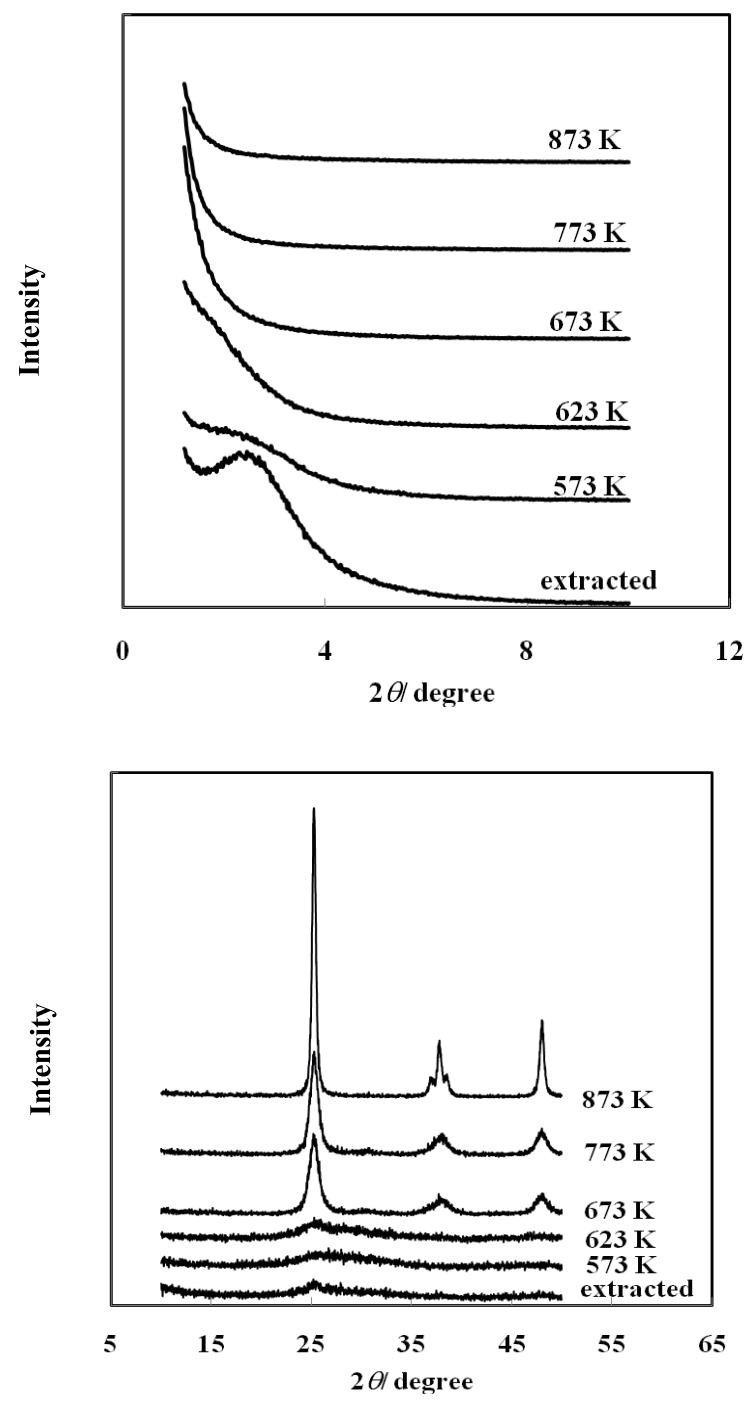

Fig. 1 XRD of meso $\mathrm{TiO}_{2}$ extracted and calcined at 573, $623,673,773$ and $873 \mathrm{~K}$. Low and high angle regions are shown separately. the diffractions from anatase structure. The intensity and the FWHM of these peaks are drastically increased and decreased, respectively, with the calcination temperature. At the calcination at $873 \mathrm{~K}$, the peak around $37.4^{\circ}$ is further resolved, suggesting the growth of anatase crystallites. It is to be noted that the low-angle peak, due to a periodic mesostructure, disappears simultaneously with the rise of anatase diffraction pattern. When we measured XRD of meso $\mathrm{TiO}_{2}$ at calcined 653 $\mathrm{K}$, the trace of the peak at $2.4^{\circ}$ was observed, whilst no peaks was found between $10^{\circ}$ and $50^{\circ}$. The simultaneous change of peaks around $673 \mathrm{~K}$ implies that a transition of framework structure occurs at this temperature.

The crystallite size estimated using the peak broadening at $2 \theta=25.3^{\circ}$ and the Scherrer's equation is 7, 9 and $25 \mathrm{~nm}$ for $673 \mathrm{~K}$-, $773 \mathrm{~K}$ - and $873 \mathrm{~K}$-calcined meso $\mathrm{TiO}_{2}$, respectively. The effect of calcination temperature on the growth of crystallite size is distinct. It should be noted that the mesoporous structure still remains after $873 \mathrm{~K}$ calcination, though the BET specific surface area decreases to be $39 \mathrm{~m}^{2} \mathrm{~g}^{-1}$.

Figure 2 shows the nitrogen adsorption/desorption isotherms of meso $\mathrm{TiO}_{2}$, with which the structural parameters were calculated. These parameters are summarized in Table 1. All plots exhibit type-IV pattern with the presence of a hysteresis loop. A major suppression of the adsorption occurs by the $573 \mathrm{~K}$-calcination, and the increase of the temperature results in gradual decrease. The surface area and pore volume shown in Table 1

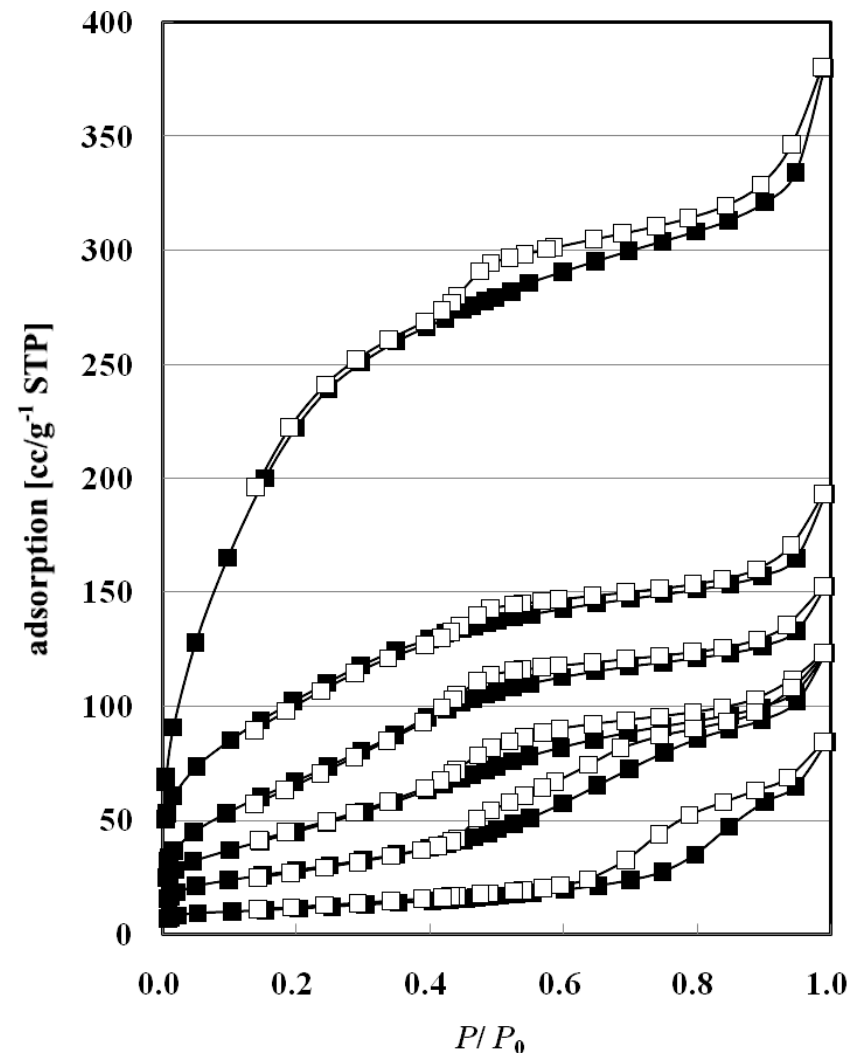

Fig. 2 Nitrogen adsorption (filled square) and desorption isotherms (open square) of meso $\mathrm{TiO}_{2}$. From top to bottom extracted, $573 \mathrm{~K}-, 623 \mathrm{~K}-, 673 \mathrm{~K}-, 773 \mathrm{~K}-$ and $873 \mathrm{~K}^{-\mathrm{TiO}_{2}}$. 
decrease with the temperature in accordance with the isotherms. In contrast, the pore size increases with calcination temperature, suggesting the shrinkage of pore wall. At $673 \mathrm{~K}$, where the framework is crystallized to be anatase, the pore diameter is widened (Table 1), suggesting a significant transformation of the mesoporous framework as well as the porous structure. The decreases of the surface area and the increase of pore size are further found with the temperature range at 673 and $873 \mathrm{~K}$, where the XRD peaks due to anatase crystal grows. The combination of the results thus suggests that crystallization into anatase degrades the surface area and mesopore volumes of the solid.

Figure 3 depicts typical Raman spectra of extracted meso $\mathrm{TiO}_{2}$. No distinct peak is found in that for extracted meso $\mathrm{TiO}_{2}$. (Fig. 3 (a)) Although we measured the spectrum ten times varying the spot of irradiation, the same pattern was always obtained. After the calcination at 493,533 and $573 \mathrm{~K}$, the peaks attributed due to rutile (259, 419 and $\left.609 \mathrm{~cm}^{-1}\right)$ and anatase (155, 399, 511 and 622 $\mathrm{cm}^{-1}$ ) were observed as shown in Figs. 3 (b) and (d). When the spot of irradiation was relocated, the obtained scattering pattern was changed. In some measurements, the observed peaks in a single spectrum were attributed to those for rutile and anatase. (Fig. 3 (c)) The observation varying the spot of irradiation revealed that the local structure of $\mathrm{Ti}$ is rutile like or anatase like after the calcination at 493-573 K, though the no distinct diffractions due to crystalline phases was observed in XRD. It is interesting that anatase and rutile local structures of Ti coexist in meso $\mathrm{TiO}_{2}$ calcined at $573 \mathrm{~K}$ and $623 \mathrm{~K}$ of the present study.

The Raman scattering pattern became that of anatase when meso $\mathrm{TiO}_{2}$ was calcined at $673 \mathrm{~K}$. In addition, no other peaks were found in this solid, whenever the spot of laser irradiation moved. It is well known that anatase and rutile have different edge sharing patterns for the connection of $\mathrm{TiO}_{6}$ octahedrons. The crystallization into anatase results in the conversion of local rutile structure into anatase through recombination of $\mathrm{TiO}_{6}$ units.

Figure 4 summarizes the frequency of observations of the spectral patterns discussed above. In the amorphous phase (calcined between 493 and $573 \mathrm{~K}$ ), the frequency of rutile, anatase and the mixed pattern are almost the

Table 1 Mesoporous structures calculated from nitrogen adsorption isotherms.

\begin{tabular}{lccc}
\hline meso $\mathrm{TiO}_{2}{ }^{\mathrm{a}}$ & $\begin{array}{c}A_{\mathrm{BET}}{ }^{\mathrm{b}} \\
{\left[\mathrm{m}^{2} \mathrm{~g}^{-1}\right]}\end{array}$ & $\begin{array}{c}V_{\mathrm{P}}^{\mathrm{c}} \\
{\left[\mathrm{cc} \mathrm{g}^{-1}\right]}\end{array}$ & $\begin{array}{c}2 R_{\mathrm{P}}{ }^{\mathrm{d}} \\
{[\mathrm{nm}]}\end{array}$ \\
\hline extracted & 836 & 0.79 & 1.7 \\
573 K-calcined & 374 & 0.34 & 1.9 \\
623 K-calcined & 257 & 0.27 & 2.4 \\
673 K-calcined & 168 & 0.20 & 3.0 \\
773 K-calcined & 101 & 0.20 & 4.0 \\
873 K-calcined & 39 & 0.13 & 10 \\
\hline
\end{tabular}

${ }^{a}$ mesoporous titania, ${ }^{b}$ BET specific surface area, ${ }^{c}$ pore volume by BJH method, and ${ }^{\mathrm{d}}$ most probable pore diameter in $\mathrm{BJH}$ distributions.
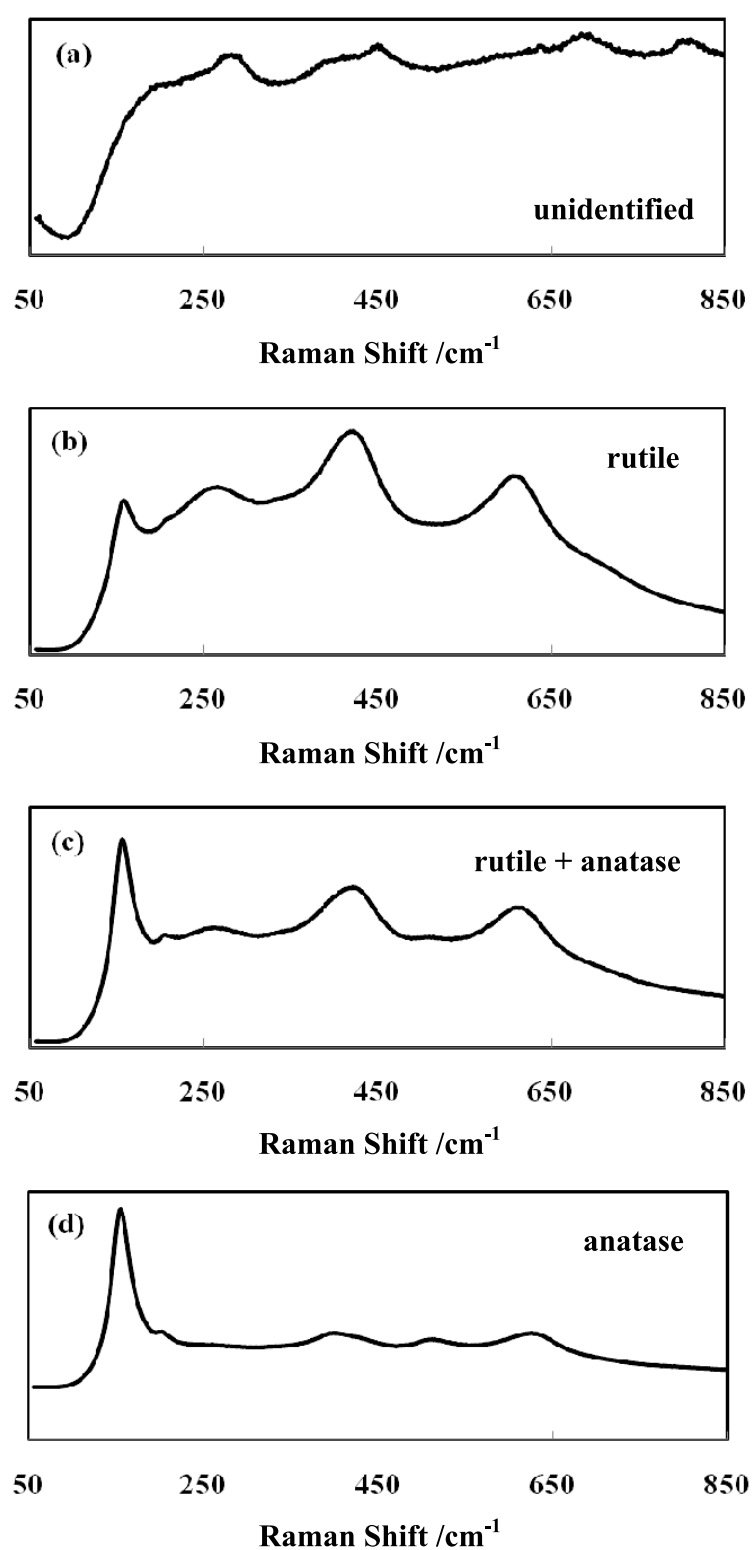

Fig. 3 Typical Raman spectroscopic patterns of meso $\mathrm{TiO}_{2}$ extracted (a) and calcined at $533 \mathrm{~K}$ (others: measured with laser irradiation at different region of sample). The irradiation spot size was $50 \mu \mathrm{m}$. The assignment of each pattern is shown in each spectrum.

same. The frequency is clearly insensitive to the calcination temperature, suggesting that the population of rutile and anatase local structures is nearly constant in amorphous mesoporous titania calcined at various temperatures. In contrast, unique spectral features, unidentified or anatase patterns, were found in extracted and $673 \mathrm{~K}$ calcined meso $\mathrm{TiO}_{2}$, respectively.

The transmission electron microscopic images of meso $\mathrm{TiO}_{2}$ extracted and calcined at $673 \mathrm{~K}$ are shown in Fig. 5. As expected from the wormhole-like structure revealed by nitrogen adsorption and XRD experiments, no well-ordered channel is clearly observed in the photographs. However, the size of pores, most of which are found as the difference in the contrast of Figs. 5(a) and (b), are uniform at $c a .2$ and $3 \mathrm{~nm}$, respectively. These sizes agree with the results in Table 1 . 


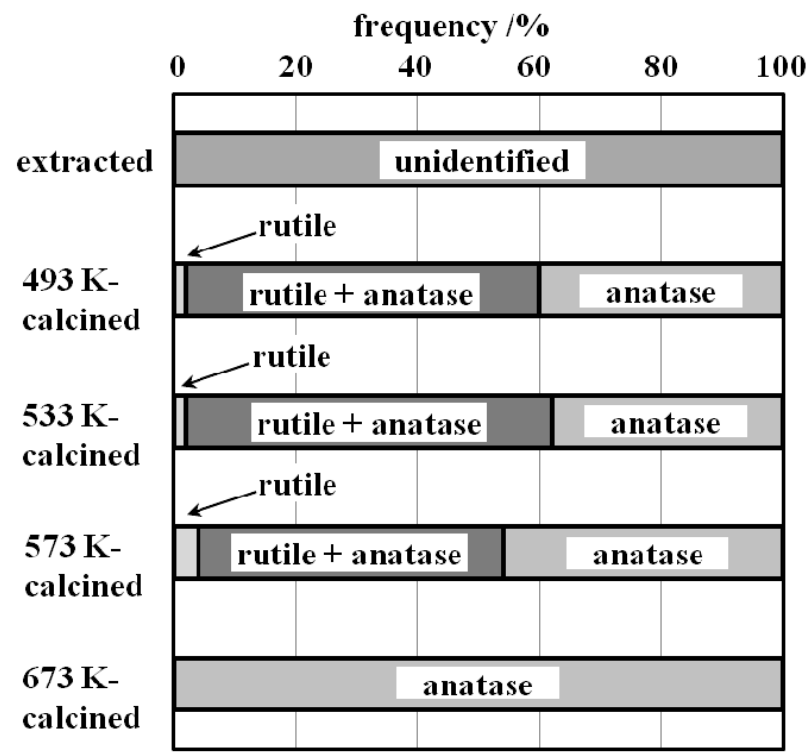

Fig. 4 Typical Raman spectroscopic patterns of meso $\mathrm{TiO}_{2}$ extracted (a) and calcined at $533 \mathrm{~K}$ (others). The assignment of each pattern is shown.

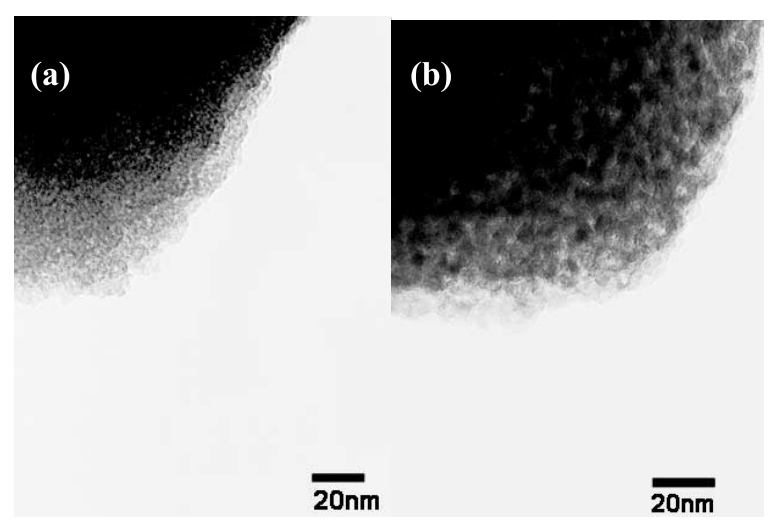

Fig. 5 Transmission micrographs of meso $\mathrm{TiO}_{2}$ extracted (a) and calcined at $673 \mathrm{~K}$ (b).

Figure 6 depicts the second discharge and charge curves of meso $\mathrm{TiO}_{2}$ electrode prepared with different calcination temperatures. The Li storage capacity is summarized in Table 1, which increases with the calcination temperature below $773 \mathrm{~K}: 124,139,149,186,225$ $\mathrm{mAh} \mathrm{g}^{-1}$ for extracted, $573 \mathrm{~K}$-calcined, $623 \mathrm{~K}$-calcined, $673 \mathrm{~K}$-calcined and $773 \mathrm{~K}$-calcined meso $\mathrm{TiO}_{2}$, respectively. The capacity for $873 \mathrm{~K}$-calcined meso $\mathrm{TiO}_{2}(184 \mathrm{mAh}$ $\mathrm{g}^{-1}$ ) is smaller than that for $773 \mathrm{~K}$-calcined powder. For electrochemical reaction, $\mathrm{TiO}_{2}+0.5 \mathrm{Li}^{+}+0.5 e \rightarrow \mathrm{Li}_{0.5} \mathrm{TiO}_{2}$, the theoretical capacity is calculated to be $168 \mathrm{mAh} \mathrm{g}^{-1}$. It is known that this reaction does not practically occur in rutile but in anatase. However, a capacity comparable to the theoretical one has been recorded for nanocrystalline rutile with a dimension of several tens of $\mathrm{nm},{ }^{2)}$ suggesting that the actual capacity of inactive "phases" cannot be predicted for crystallites with a particle size in nm.

The obvious plateau appears in $673 \mathrm{~K}-, 773 \mathrm{~K}$ - and 873 K-calcined meso $\mathrm{TiO}_{2}$ just as anatase electrodes. ${ }^{1,14,15)}$ The
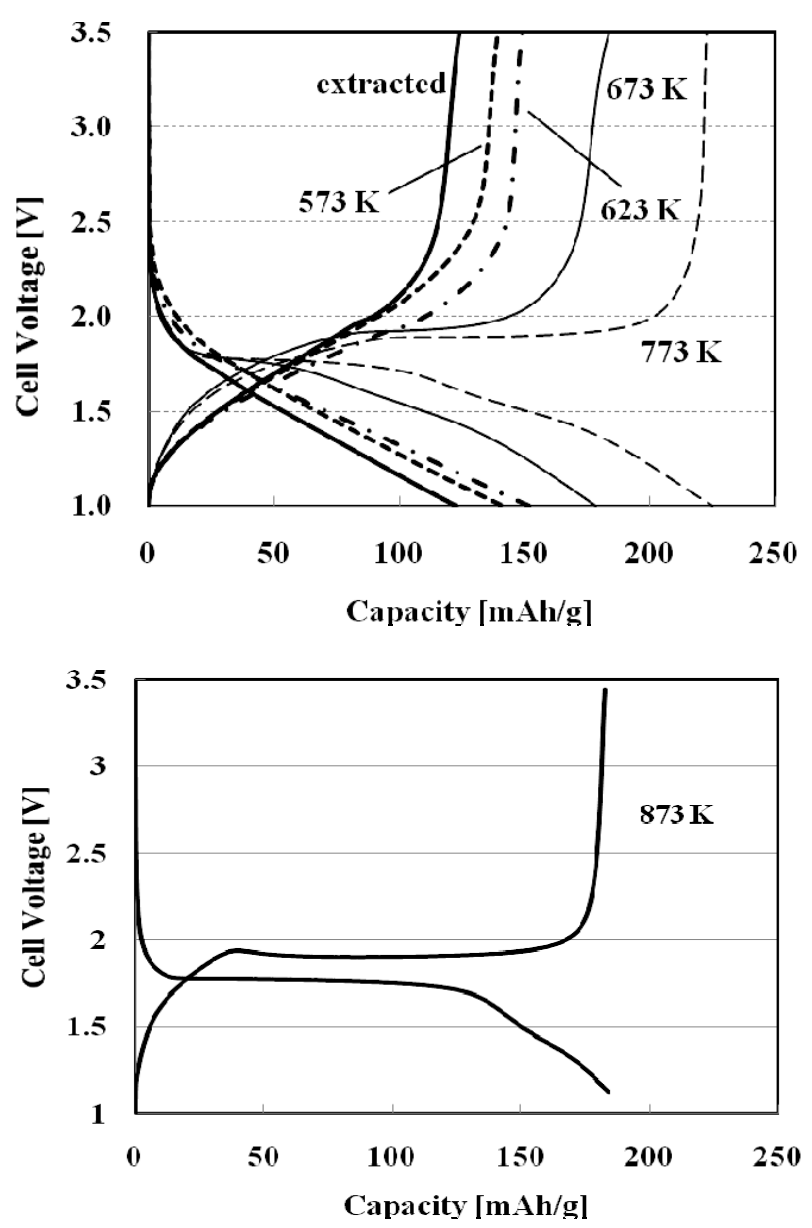

Fig. 6 The discharge-charge curves of extracted $\mathrm{TiO}_{2}$, compared with 573K-, $623 \mathrm{~K}-, 673 \mathrm{~K}-, 773 \mathrm{~K}-$ and $873 \mathrm{~K}$ calcined meso $\mathrm{TiO}_{2}$. The rates were $0.1 \mathrm{C}\left(=16.8 \mathrm{~mA} \mathrm{~g}^{-1}\right)$ and the second cycle was recorded.

lack of plateaux in meso $\mathrm{TiO}_{2}$ in the amorphous phases (i.e. those extracted and calcined 573-623 K) suggests that the chemical potential of $\mathrm{Li}^{+}$changes nearly continuously with the composition of the electrode. However, it was able to find the inflection points in the charge-discharge curves for these amorphous phases when we converted these data into $\mathrm{d} Q / \mathrm{d} V$ vs $V$ plots. The results are summarized in Table 2.

It should be remarked that the capacity clearly increase with the calcination temperature in the amorphous meso $\mathrm{TiO}_{2}$, though we did not find significant differences in XRD patterns in $2 \theta=10^{\circ}-50^{\circ}$ and Raman spectrum among mesoporous titanias calcined between 493 and $653 \mathrm{~K}^{17}$

The pore wall in the meso $\mathrm{TiO}_{2}$ is estimated to be 2.0 $\mathrm{nm}\left(d-2 R_{\mathrm{P}}=3.7-1.7\right)$. The same calculation can be applied to $573 \mathrm{~K}$ - and $623 \mathrm{~K}$-calcined meso $\mathrm{TiO}_{2}$ to obtain for their wall thickness in the framework. They are 2.6 and $3.2 \mathrm{~nm}$, respectively. For $673 \mathrm{~K}$-calcined meso $\mathrm{TiO}_{2}$, the anatase particle size can be calculated based on the phonon confinement model with the peak shift of $E_{\mathrm{g}}$ band in Raman spectrum. ${ }^{17)}$ It is $4 \mathrm{~nm}$, which is slightly smaller than that is estimated in XRD line broadenings $(7 \mathrm{~nm})$. These thicknesses are comparable to the 
nanocrystalline rutile that shows a $\mathrm{Li}$ storage capacity. ${ }^{2)}$ Measurable capacities imply that the $\mathrm{Li}$ is stored in meso $\mathrm{TiO}_{2}$ whatever the framework phase is. The result, $Q($ extracted $)<Q(573 \mathrm{~K})<Q(623 \mathrm{~K})<Q(673 \mathrm{~K})$, shows that the crystalline anatase has the largest capacity and the amorphous phase has the smallest in meso $\mathrm{TiO}_{2}$. Since the pore wall thickness is smaller in extracted meso $\mathrm{TiO}_{2}$ than $673 \mathrm{~K}$-calcined one, the order in specific capacity can be applied probably for titania in amorphous and anatase phases in general. The difference between $573 \mathrm{~K}$-calcined and $623 \mathrm{~K}$-calcined meso $\mathrm{TiO}_{2}$ cannot be explained by their pore wall thickness. Considering that the decrease in particles size causes an increase in the capacity for both anatase and rutile phases, $Q(573 \mathrm{~K})<Q(623 \mathrm{~K})$ is clearly a contradictory result. This is thus due to the growth of anatase and rutile local structures in the amorphous phase.

The crystalline phase is basically anatase between 673 $\mathrm{K}, 773 \mathrm{~K}$ and $873 \mathrm{~K}$ calcinations and the crystallite sizes are different among these calcination temperatures. The origin of the difference is partially explained by the particle size. The capacity of anatase with a diameter of 6 $\mathrm{nm}$ and rutile in a dimension of $10 \mathrm{~nm} \times 40 \mathrm{~nm}$ have been reported to be 234 (at $0.6 \mathrm{C}^{1}$ and $160 \mathrm{mAh} \mathrm{g}^{-1}$ (at $0.05 \mathrm{C})^{2}$, respectively. The former value is larger than the theoretical capacity $\left(168 \mathrm{mAh} \mathrm{g}^{-1}\right)$. The enhancement of the capacity has been explained by the surface relaxation. ${ }^{1,18)}$ In the present result, the crystallite size of 673 $\mathrm{K}$-calcined meso $\mathrm{TiO}_{2}$ is almost the same as the above mentioned rutile nanoparticles, though the capacity is distinctly smaller. In contrast, the crystallite size of 773 $\mathrm{K}$-calcined meso $\mathrm{TiO}_{2}$ is larger than $6 \mathrm{~nm}$ while its capacity is nearly the same as that of $6 \mathrm{~nm}$ anatase. The difference is probably due to the connection of particles to form the framework of $673 \mathrm{~K}$-calcined meso $\mathrm{TiO}_{2}$ and the transformation of the surface atomic structure that enhances the Li storage capacity in anatase nanoparticles. And the curvature of the surface is possibly related with the difference in the storage of $\mathrm{Li}^{+}$between nanoparticles and mesoporous anatase.

Figure 7 shows the cycle performance of extracted and $673 \mathrm{~K}$-calcined meso $\mathrm{TiO}_{2}$ electrodes at $0.1 \mathrm{C}$. The capacity of the $673 \mathrm{~K}$-calcined mesoporous electrode is stable except the drop in the first cycle. It remains at $153 \mathrm{mAh} \mathrm{g}^{-1}$ (for both discharge and charge processes)

Table 2 Specific capacities and plateau voltages in chargedischarge curves of mesoporous $\mathrm{TiO}_{2}$ electrodes. ${ }^{a}$

\begin{tabular}{lccc}
\hline meso $\mathrm{TiO}_{2}$ & $\begin{array}{c}Q \\
{\left[\mathrm{mAh} \mathrm{g}^{-1}\right]}\end{array}$ & $\begin{array}{c}V_{\text {ch }} \\
{[\mathrm{V}]}\end{array}$ & $\begin{array}{c}V_{\text {dis }} \\
{[\mathrm{V}]}\end{array}$ \\
\hline extracted & 124 & $1.98^{b}$ & $1.76^{b}$ \\
573 K-calcined & 139 & $1.98^{b}$ & $1.76^{b}$ \\
623 K-calcined & 152 & $1.94^{b}$ & $1.75^{b}$ \\
673 K-calcined & 186 & 1.92 & 1.78 \\
773 K-calcined & 225 & 1.90 & 1.79 \\
873 K-calcined & 184 & 1.90 & 1.79 \\
\hline
\end{tabular}

${ }^{a}$ The rates of charge and discharge were $0.1 \mathrm{C}\left(=16.8 \mathrm{~mA} \mathrm{~g}^{-1}\right)$.

${ }^{b}$ Inflection points found by converting the data into $\mathrm{d} Q / \mathrm{d} V$ vs $V$ plots.

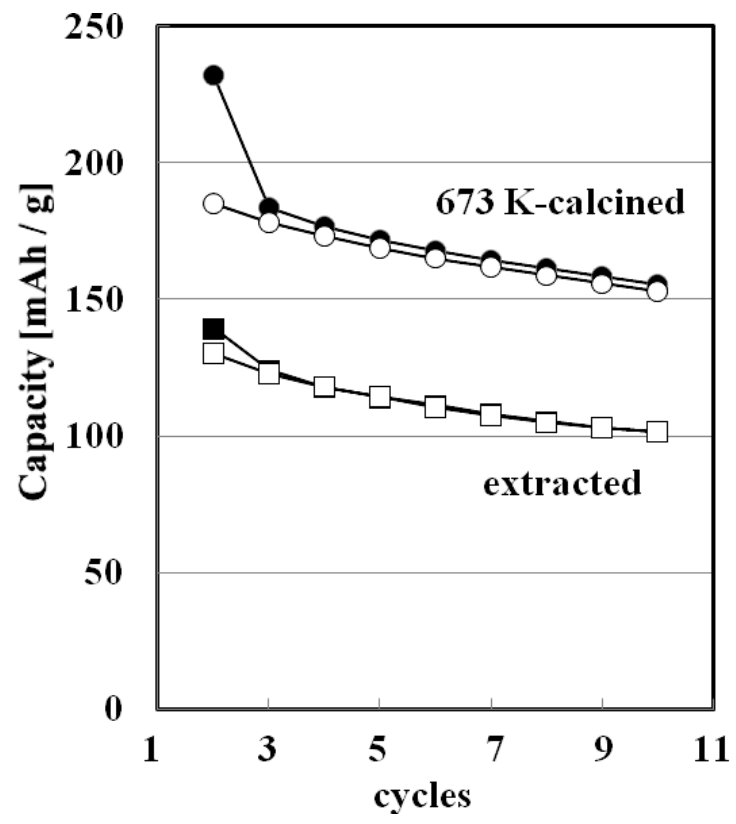

Fig. 7 Cycle performance of extracted and $673 \mathrm{~K}$-calcined meso $\mathrm{TiO}_{2}$ electrode. Charge (filled dots) and discharge (open dots) rates were $0.1 \mathrm{C}\left(=16.8 \mathrm{~mA} \mathrm{~g}^{-1}\right)$.

after the tenth cycle. On the other hand, even the initial large drop is absent in extracted mesoporous titania electrode. The capacity is $101 \mathrm{mAh} \mathrm{g}^{-1}$ (for both discharge and charge processes) after nine cycles. Since the amorphous phase does not contain the distinct particle boundaries, the initial drop is likely due to the stabilization by minor transformation and/or recombination at the particle boundaries in the anatase mesoporous framework.

The plateaux in discharge-charge curves are changed according to the calcination temperature as shown in Table 1; the voltage for the plateau in the charge process is decreased while it is slightly increased. These shifts imply that the $\mathrm{Li}^{+}$-insertion reaction becomes more and more reversible with the growth of anatase crystalline structure. In addition to the plateaux much more vague in amorphous meso $\mathrm{TiO}_{2}$ than in anatase meso $\mathrm{TiO}_{2}$, the lack of the reversibility is probably due to poorly developed Li channels in the framework in amorphous phase.

We also recorded discharge and charge curves at 1 and $10 \mathrm{C}$ using fresh extracted meso $\mathrm{TiO}_{2}$ electrodes. The distinct decrease of the capacity was found in the processes at $1 \mathrm{C}$ such as $Q$ (extracted $)=0.025 \mathrm{~mA} \mathrm{~g}^{-1}$. This capacity did not change significantly at $10 \mathrm{C}$. It is clear that the drop of the specific capacity appears at smaller charge/discharge current than the other oxide cathode materials in the electrochemical works in the related materials of this study. ${ }^{1-3,5,12,18)}$ Although it is not certain that this is due to its mesoporous structure, a low capacity at high current will limit the potential application for the Li batteries. Further study on the influence of mesopore size on the specific capacity is necessary.

\section{Conclusion}

This work demonstrates Li storage in amorphous and 
anatase mesoporous titanias with the pore size from 2 to $10 \mathrm{~nm}$. The discharge/charge capacity increases with the calcination temperature until $773 \mathrm{~K}$. When the solid is calcined at $673 \mathrm{~K}$, the framework is crystallized to be anatase and the capacity increases to $186 \mathrm{mAh} \mathrm{g}^{-1}$. We obtained maximum capacity $225 \mathrm{mAh} \mathrm{g}^{-1}$ for the calcination at $773 \mathrm{~K}$. The gap in plateaux between charge and discharge processes found in $V$ - $\mathrm{d} Q / \mathrm{d} V$ plots varies according to the change in framework structure of mesoporous titania.

\section{Acknowledgement}

The authors thank the New Energy and Industrial Technology Development Organization for its financial support. They also thank Prof. Masayoshi Watanabe (YNU) and the members of his research group for their kind assistance for manipulation of the glove box. The transmission microscopy was operated by Mr. M. Kondo in the instrumental analysis centre of YNU.

\section{References}

1) C. Jiang, M. Wei, Z. Qi, T. Kudo, I. Honma, and H. Zhou, J. Power Sources, 166, 239 (2007).

2) Y. Hu, L. Kienle, Y. Guo, and J. Maier, Adv. Mater., 18, 1421 (2006).

3) C. Jiang, I. Honma, T. Kudo, and H. Zhou, Electrochem. Solid State Lett., 10, A127 (2007).

4) L. D. Noailles, C. S. Johnson, J. T. Vaughey, and M. M. Thackeray, J. Power Sources, 81-82, 259 (1999).

5) A. Kuhn, R. Amandi, and F. Garcia-Alvarado, J. Power Sources, 92, 221 (2001).
6) M. Zukalova, M. Kalbac, L. Kavan, I. Exnar, and M. Graetzel, Chem. Mater., 17, 1248 (2005).

7) D. Antnolli, Microporous Mesoporous Mater., 30, 315 (1999).

8) P. Yang, D. Zhao, D. I. Margolese, B. F. Chmelka, and G. D. Stucky, Nature, 396, 152 (1998).

9) H. Shibata, H. Mihara, T. Mukai, T. Ogura, H. Kohno, T. Ohkubo, H. Sakai, and M. Abe, Chem. Mater., 18, 2256 (2006).

10) H. Yoshitake, T. Sugihara, and T. Tatsumi, Chem. Mater., 14, 1023 (2002).

11) K. H. Reiman, K. M. Brace, T. J. Gordon-Smith, I. Nandhakumar, G. S. Attard, and J. R. Owen, Electrochem. Commun., 8, 517 (2006).

12) D. Wang, D. Choi, Z. Yang, V. V. Viswanathan, Z. Nie, C. Wang, Y. Song, J. Zhang, and J. Liu, Chem. Mater., 20, 3435 (2008).

13) D. Fattakhova-Rohlfing, M. Wark, T. Brezesinski, B. M. Smarsly, and J. Rathousky, Adv. Funct. Mater., 17, 123 (2007).

14) H. Lindstroem, S. Soedergren, A. Solbrand, H. Rensmo, J. Hjelm, A. Hagfeldt, and S. Lindquist, J. Phys. Chem. B, 101, 7717 (1997).

15) F. Leroux, P. J. Dewar, M. Intissar, G. Ouvrard, and L. F. Nazar, J. Mater. Chem., 12, 3245 (2002).

16) H. Yoshitake, T. Sugihara, and T. Tatsumi, Phys. Chem. Chem. Phys., 5, 767 (2003).

17) H. Yoshitake and D. Abe, Microporous Mesoporous Mater., 119, 267 (2009).

18) M. Okubo, E. Hosono, J. Kim, M. Enomoto, N. Kojima, T. Kudo, H. Zhou, and I. Honma, J. Am. Chem. Soc., 129, 7444 (2007). 